\title{
Research on Land Utilization Based on DEA-BP Neural Network Model
}

\author{
Bihe Fang ${ }^{1, a}$, Tingyi Zhao ${ }^{2, b}$ \\ ${ }^{1}$ Department of Management, Hefei University of Technology, Anhui, 230009, China \\ ${ }^{2}$ Department of Management, Hefei University of Technology, Anhui, 230009, China \\ aemail:f7965@126.com, bemail:948398452@qq.com
}

Keywords: Land Utilization; DEA; BP Neural Network

\begin{abstract}
This paper comes up with a DEA-BP Neural Network Model which demands little on the input data and owns a good ability to foresight. The writer use the data from Project named The Evaluation on Development Land Utilization to test DEA-BP Neural Network Mode. The result indicates that the model performs well on land utilization evaluation.
\end{abstract}

\section{Introduction}

As China's industrialization and urbanization, economic and technological development zones develop rapidly. However, land utilization has faced some dilemma such as attaching too much importance to expansion and giving too little care to tapping the potential [1]. These problems result in land vacancy and low usage rates. What's more, all of them restrict developments' further advancement. How to guarantee socioeconomic sustainable development, build resource-conserving society and prevent expansion without destination has been an important issue at home and abroad.

Multi-index comprehensive evaluation method is the most popular way of all the evaluation methods [2]. But multi-index comprehensive evaluation method lacks the ability to define intensive land utilization and is too subjective. What's more, it is hard to confirm reference value [3] .On account of these, the writer came up with DEA-BP Neural Network Model to deal with the quantitative data of land. The model is fit for multi-input and multi-output system and owns the ability to predicate accurately. The writer used the basic data from 118 land disputes of some development belonging to Anqing to test the model. The experiment's result supports that the model is suit for land evaluation and owns good robustness.

\section{DEA-BP Neural Network Model}

Data Envelopment Analysis (DEA) was invented by Charnes, Cooper and Rhodes in 1978. It is a classical CCR model. The core thought of DEA is to establish efficient frontier to get relative efficiencies of all decision making unit (DMU).

DEA owns particular advantages to deal with multi-input and multi-output system for it can determine weights automatically and don't need to research the unction relationships among all indexes. The most attractive point is that DEA can help human to find out why a DMU is inefficiency and then point out how to promote DMU. As it showed up, DEA theory attracts the attention of all over the world and gets developed rapidly. Many models which own different characteristics and functions such as DEA Overlapping Efficiency Model, DEA Confidence Interval Model, DEA Super-efficiency Model have been put forward constantly.

DEA has been proved to can play an efficient role in many domains including hotel's efficiency evaluation, bank system's performance evaluation and port's efficiency evaluation. It has been a mature and widely applicable means of comprehensive evaluation means [4].

Doc W.S.McCulloch came up the concept of neural network and built a mathematic model named MP Model with W.Pitts. Neural network need not to figure out the function relationship among indexes. It opened a new era of artificial neural network ever since. Back-propagation neural network (BP Neural network) is a supervised learning algorithm which is often used to train multilayer perceptrons. As BP Neural network works out multilayer feedforward neural network 
weights adjustment problems of nonlinear continuous function, over $90 \%$ of practical applications can be assigned to BP Neural network and its extensive forms.

Through a large number of researches and demonstrations by scholars, people are conscious of BP Neural network's mapping ability, self-learning ability, self-adaption ability, prediction ability and fault-tolerant ability. Although BP Neural network is unable to simulate how a brain works completely, it has played a huge role in neural expert system, pattern recognition, intelligent control, and combinatorial optimization since its ability to solve unstructured data analysis such as speech and image data processing which is hard for compute to deal with. On the other hand, the combination of neural network and other means will drive artificial intelligence and data mining to keep develop persistently.

The input and output vector quantities of $\mathrm{DMU}_{\mathrm{i}}$ respectively are

$$
\begin{aligned}
& X_{i}=\left(x_{i 1}, x_{i 2}, \ldots, x_{i s}\right)^{T} \\
& Y_{i}=\left(y_{i 1}, y_{i 2}, \ldots, y_{i p}\right)^{T}
\end{aligned}
$$

The corresponding weight vectors are

$$
\begin{aligned}
& \mathrm{Vi}=\left(\mathrm{v}_{\mathrm{i} 1}, \mathrm{v}_{\mathrm{i} 2}, \ldots, \mathrm{v}_{\mathrm{is}}\right) \\
& \mathrm{Ui}=\left(\mathrm{u}_{\mathrm{i} 1}, \mathrm{u}_{\mathrm{i} 2}, \ldots, \mathrm{u}_{\mathrm{ip}}\right)
\end{aligned}
$$

Aimed to maximize the index of the assessment of efficiency and restrained by all other DMU's efficiency index, the $\mathrm{DMU}_{\mathrm{i} 1}$ 's planning model is presented as

$$
\begin{aligned}
& \max \frac{u^{T} Y_{i 1}}{v^{T} X_{i 1}} \\
& \text { s.t. } \frac{u^{T} Y_{i 1}}{v^{T} X_{i 1}} \leq 1 \quad \mathrm{i}=1,2, \ldots, \mathrm{n} \\
& \mathrm{u}_{\mathrm{k}} \geq 0, \mathrm{i}=1,2, \ldots, \mathrm{n} \\
& \mathrm{v}_{\mathrm{j}} \geq 0, \mathrm{j}=1,2, \ldots, \mathrm{n}
\end{aligned}
$$

After Transform - Cooper Charnes:

$$
\begin{aligned}
& t=\frac{1}{v^{T} X_{i 1}} \\
& \mathrm{w}=\mathrm{tv} \\
& \mathrm{u}=\mathrm{tu}
\end{aligned}
$$

The CCR Model comes to this

$\max u^{T} Y_{i 1}$

s.t. ${ }^{\mathrm{T}} \mathrm{X}_{\mathrm{i}}-\mathrm{u}^{\mathrm{T}} \mathrm{Y}_{\mathrm{i}} \geq 0, \quad \mathrm{i}=1,2, \ldots, \mathrm{n}$

$\mathrm{w}^{\mathrm{T}} \mathrm{X}_{\mathrm{i} 0}=1$,

$\mathrm{w} \geq 0, \mathrm{u} \geq 0$

BP neural network uses the relative efficiencies calculated by DEA as its expected output. And then the writer used Linear transformation algorithm to preprocess the relative efficiencies, the Linear transformation algorithm is

$$
y=\frac{(x-\min )}{(\max -\min )}
$$

Min replaces the minimum value, max replaces the maximum value. (1.7) normalizes input $\operatorname{data}(\mathrm{x})$ to interval[0,1].

The BP neural network in DEA-BP Neural Network Model lays emphasis on its prediction function. So the proportion of predicated object is bigger than others[6][7].

Some scholars indicated that a neural network with one hide layer can simulate any continuous function in a closed interval[8].Therefore DEA-BP Neural Network Model adopt a neural net with one hide layer.

Considering over-fitting and its performance, the BP neural net determines the account of hide layer's nerve cell by the empirical formulas (1.8), (1.9), (1.10).

$$
l=\sqrt{n+m}+a
$$




$$
\begin{aligned}
& l=\log _{2} n \\
& l \leq \sqrt{m(n+3)+1}
\end{aligned}
$$

$\mathrm{L}$ represents the sum of nerve cell, $\mathrm{n}$ represents the account of positive nerve cell, $\mathrm{m}$ represents negative nerve cell, a ranges from 1 to 10 .

The DEA-BP Neural Network Model chooses Logarithmic transfer function as its activation function.

$$
y=\frac{1}{1+e^{-x}}
$$

And finally, the writer design formula (1.12) to describe prediction accuracy

$$
y=\frac{\text { hitNum }}{\text { sum }} * 100 \%
$$

\section{Applying DEA-BP Neural Network Model to Development Land Utilization Evaluation}

The basic data (118 enterprises) comes from a project about evaluation on land intension and economize of some development belonging to Anqing. Some enterprises in the development were built lately and their equipments have not been brought on stream. So some data is 0 . However, Considering to DEA requires (input data to should not be 0 ), the writer used 0.001 to replace 0 in the experiment.

In consideration of model's practicality, consistency, independence and testability, the writer choose these index variables as input variables: site area(X1), gross fixed asset formation(X2) and the output variables are general income (Y1), building density (Y2), basal area(Y3).

The writer used MATLAB R2010a to accomplish the whole process of CCR Model. And the Relative Efficiencies of all DMU is show in Fig .1

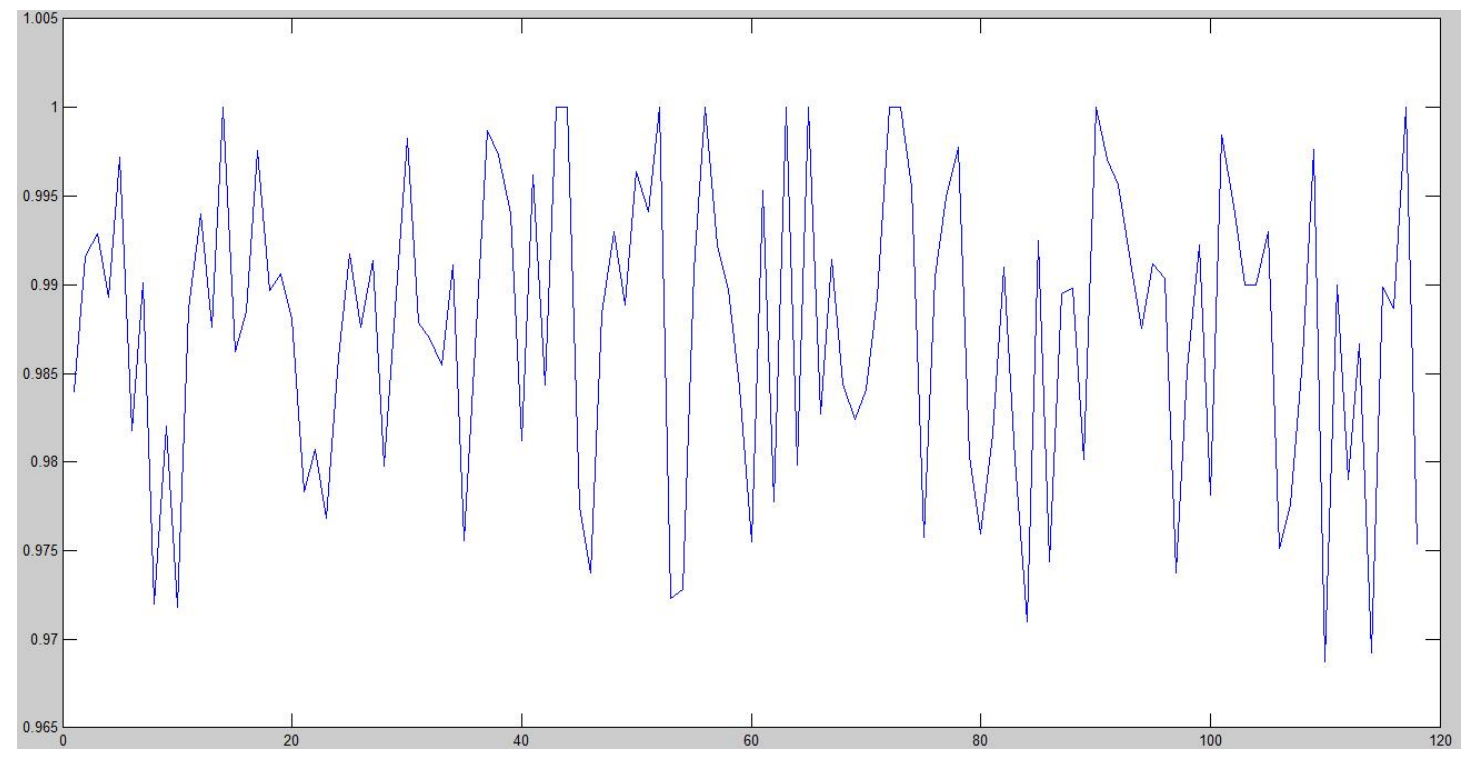

Fig.1 the relative efficiencies of Enterprises

As we can see, the relative efficiencies of all enterprises vary from 0.956 to 1.00 and plenty of enterprises reach to 1.00 . It means that the land utilization of this development has got to a high level. When the writer was involved in the project, the writer found that the development has been a mature development for a long time and its management is impeccable especially it controls the supply of land by revenue. The achievement of the project indicates that there is no block of land that left unused. It accords with the relative efficiencies calculated by CCR Model highly. So it is reasonable to adopt DEA to measure land utilization.

After verifying the effectiveness of DEA, the writer used the relative efficiencies as expected output to BP neural network. Although the relative efficiencies of all enterprises in the development are high, the writer expanded the interval to $[0.8,1.0]$ since land utilization varies so greatly from 
development to development [5].

The writer divided 118 enterprises into 70 training objects and 48 testing objects and chose function TRAINGDX as the adaption-learning function. After several tests, the expected error is 0.01 finally and the learning rate is 0.01 too. On this occasion, the model provides an excellent performance.

\section{Test results}

The BP neural network reached to expert errs after 112 iterations in one experiment and the predicting accuracy reached up to $91.667 \%$.

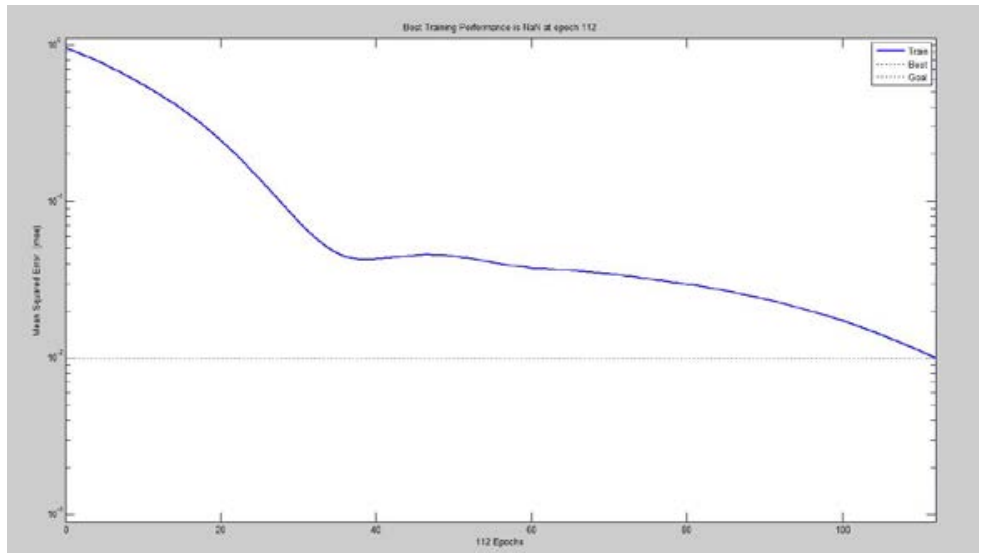

Fig.2 The Training Tendency of BP Neural Net

To verify the robustness of the model, the writer trained the model for 100 times, and recorded all predicting accuracy of experiments. The writer portrayed the statistical chart of predicting accuracy by MATLAB, and portrayed the chart of predicting accuracy by EXCEL 2007.

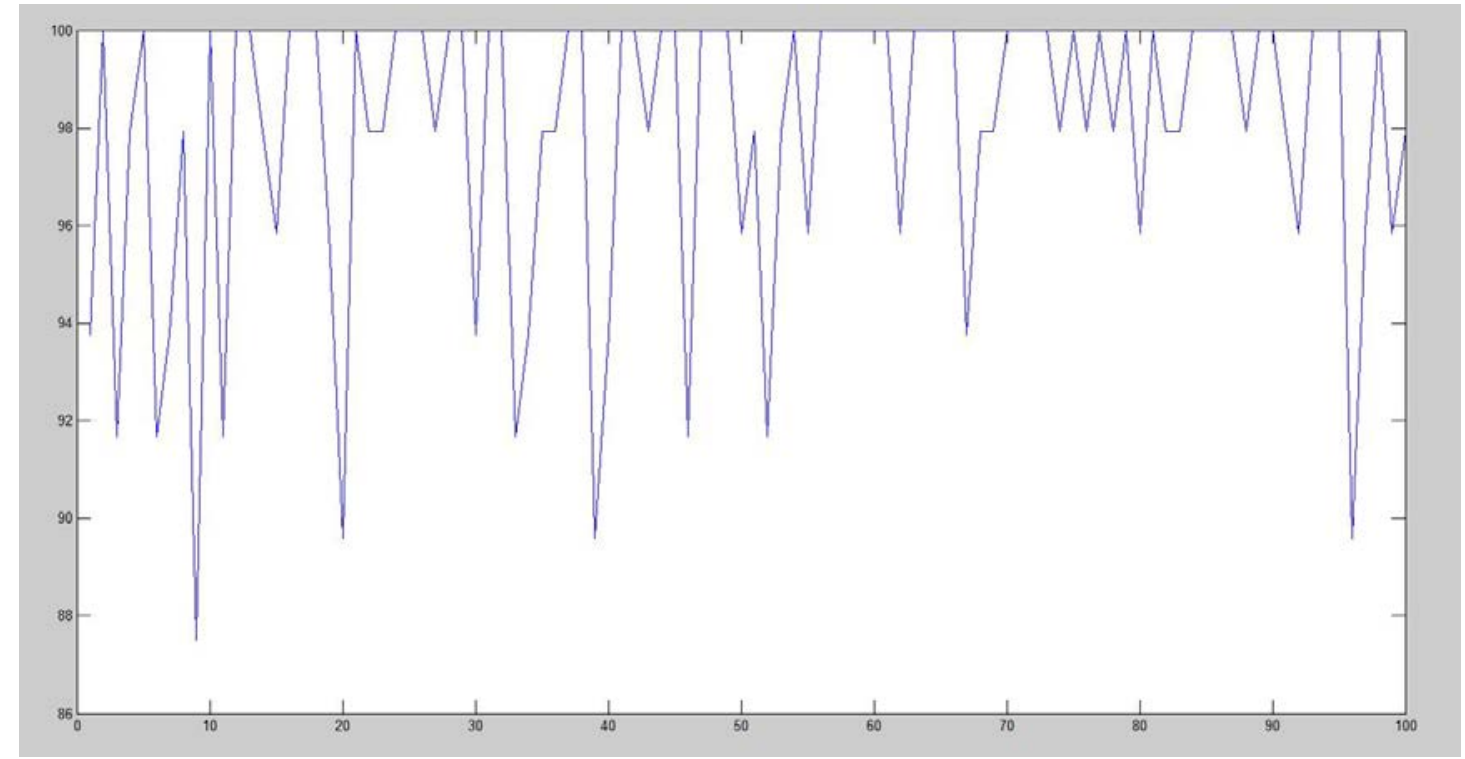

Fig.3 the Predicting Accuracy Summarizing of BP Neural Net Table.1 the Statistics of Predicting Accuracy

\begin{tabular}{ccc}
\hline Interval & Count & Frequency \\
\hline$[87.5,90.0)$ & 4 & 0.04 \\
{$[90.0,92.5)$} & 6 & 0.06 \\
{$[92.5,95.0)$} & 6 & 0.06 \\
{$[95.0,97.5)$} & 9 & 0.09 \\
{$[97.5,100]$} & 75 & 0.75 \\
Maximum & 100 & $/$ \\
Minimum & 87.50 & $/$ \\
Average & 97.875 & $/$ \\
\hline
\end{tabular}


We can draw a conclusion from the whole experience that BP neural network owns the predicting accuracy reaching to $97.875 \%$ and it keeps stable. It demonstrates that DEA-BP Neural Network is appropriate for land utilization.

\section{Conclusion}

After sufficient studying at DEA and BP neural net, this paper comes up with DEA-BP Neural Network Model. The model combines the advantages of DEA and BP neural network. Then the writer tested the model with 118 enterprises from a development .The experiment proves that the model is feasible and accurate when adopted to land utilization.

\section{Acknowledgement}

In this paper, the project was sponsored by the Land Resources Bureau of Anhui Province (Project No.10-917).

\section{References}

[1] Liguo Sun. Research on the Credit Evaluation of Small and Mid-small Scientific and Technological Enterprise[D]. Tianjin University,2012.

[2] Zhihui Zhang. Research on China's Urban Land Use Efficiency[J]. Quantitative \& technical economics,2014,07:134-149.

[3] Aiming Wang. The Problems and Troubles of Research on Urban Land Intensive Utilization[J]. Journal of Chongqing University(JCR Social Science Edition), 2010,04:7-10.

[4]F.Joseph,J.R.Hair.MultivariateDataAnalysiswithReading,4thEdition[M].Pretice-HallInternationa 1,Inc1995:374.

[5] Dan Tan, Xianjin Huang,Chuzhi Hu,Li Yao,Feng Zhou,Liming Zhou. Comparative Study of Different Industries of Industrial Land Intensive Utilization—-Take Typical District in Jiangsu for Example[J], Jiangxi Science,2008,06:922-927.

[6] Hongtao Shi,Jinglin Yang,Maosheng Ding,Jinmei Wang. Prediction of Short-term Wind Electricity Power Based on BP Wavelet Neural Network[J]. Automation of Electric Systems, 2011, $16: 44-48$.

[7] Li Huang,Research on BP Neural Net's Improvement and Application[D]. Chongqing Normal University,2008.

[8] Huayu Shen,Zhaoxia Wang,Chengyao Gao,Juan Qin,Wei Xu.The Determination Methods of The Number of Nerve Cell of BP Neural Net's Hidden Layer[J]. Journal of Tianjin Polytechnic University,2008,05:13-15. 